\title{
Money Mathematics: Examining Ethics Education in Quantitative Finance
}

\author{
Jason West \\ Griffith University, Australia
}

\begin{abstract}
The field of quantitative analysis is often mistaken to be a discipline free from ethical burdens. The quantitative financial analyst or "quant" profession holds a position of significant responsibility as the keeper of mathematical models used in complex derivative security pricing and risk management. Despite this responsibility very few postgraduate programs address the teaching of ethics and professional standards in their curriculum, and the credibility of the profession has suffered as a result of several high-profile financial losses. Some of these failures could have been avoided and their impacts diminished if ethical considerations were integrated with quantitative method. Appropriate development in ethics education for quants is needed to identify points in the decision-making process where ethical questions can arise, and to explain how quants can protect stakeholders from the costs of unethical behaviour. An approach to ethics education needs to be flexible and allow for different methods to infuse ethical coverage into the course. Such an approach will go some way towards aligning the profession with other specialisations in banking and avoid the need for complex and unnecessary regulation.
\end{abstract}

Keywords: quantitative finance, ethics education, professional standards, mathematical models.

\section{Introduction}

The expansion of the financial markets along with the individuals, corporations, and financial intermediaries participating in them has led to a number of consequences. First, the volume of people employed in the finance profession has grown substantially. A second consequence is the decline of traditional barriers between segmented markets and the development of new financial instruments driven by increasing competition. From this a need has been created to establish specialised competence and service as a means of differentiating skills and expertise among financial institutions. Lastly finance professionals are employed by firms competing for assets and profits in a more organised and systematic manner. This has resulted in greater task specialisation which has encouraged the hiring of individuals equipped with intimate knowledge of asset pricing.

The increased complexity of financial instruments stimulated the need for a mathematical approach to security pricing. Specialised master's degrees have grown in many fields such as health care and the sciences, and finance is no exception. The master's degree in quantitative finance, which combines maths, computer science and business strategy, has grown in both stature and recognition since the mid-1990s. The role of a quantitative financial analyst or "quant" is to 
use mathematical techniques, computing technology and data manipulation to solve complex problems associated with asset pricing, trading and risk control in financial services. Quants work in such diverse fields as constructing stock portfolios, designing statistical arbitrage trading strategies and analysing data to define consumer shopping habits.

A little regarded fact is that quants typically hold positions of responsibility that are greater than what their job title suggests. Specialisation in financial mathematics is required for the valuation and risk management of complex derivatives and a deep understanding of the mathematics involved is often beyond the grasp of company executives. Financiers and traders who are subject to ethics oversight and professional codes of conduct, rely heavily on the quants to create and maintain complex mathematical models, while the quants themselves are left to operate in a relative ethics vacuum. The practice of quantitative finance rarely strays from mathematical principles or the search for computational efficiency and an appreciation for the ethical responsibilities of their role, beyond very basic internal bank compliance training, usually goes unchecked.

This study examines the evolution of the roles and responsibilities of quants in the financial services sector and the key ethical considerations of their role. We examine the motivations sustaining the growth of the quantitative finance education market and conduct a broad assessment of the differentials in business ethics education between mathematical finance and more general finance programs, including the MBA. This will highlight that the absence of ethics education in mathematical finance is a significant contributor to deficiencies in financial risk management and asset valuation, which imposes heretofore unaccounted risks. Ethical considerations for a selection of typical scenarios confronting the quant profession are discussed. The terms quantitative finance, mathematical finance and financial engineering are used interchangeably through this article.

\section{A Brief History of Mathematical Finance and Quantitative Finance Education}

The history of mathematical finance starts with Théorie de la Spéculation published 1900 by Louis Bachelier (Bachelier 1900). This analysis, revolutionary at the turn of the century, used a stochastic process known as Brownian motion to model stock prices and then price stock options, however it gained little attention in academia and even less appreciation from the banking sector. The portfolioselection work of Markowitz (1952) and Sharpe (1963) introduced mathematics to the so-called "black art" of investment management. The work of Samuelson and Merton (1974) allowed one-period discrete-time models to be replaced by continuous time, Brownian-motion models while the quadratic utility function implicit in mean-variance optimisation was replaced by more general increasing, 
concave utility functions. With time however, financial analysis has become much more sophisticated.

Arguably the major revolution in mathematical finance came with the work of Fischer Black and Myron Scholes along with fundamental contributions by Robert C. Merton, who modelled financial markets using stochastic models (Black and Scholes 1973, Merton 1973). Even more sophisticated mathematical models have since been derived such as, inter alia, multi-factor market models, parametric copulas and extreme value theory to manage investments in fixed income, foreign exchange, commodities and debt, as well as hybrids among these asset classes. As much as traditional bankers reject the notion, quantitative analysts have greatly altered the financial landscape in terms of new approaches to asset pricing, trading strategies and computational efficiency.

Growth in the number and location of financial mathematics education programs has subsequently paralleled the growth in the financial engineering profession, with its progressive influence across many aspects of financial services. The first formal postgraduate quantitative finance program was offered through the Stuart School of Business at the Illinois Institute of Technology in 1990. Rival programs were developed in 1994 by the Polytechnic Institute of New York University which offered a financial engineering degree and Carnegie Mellon who offered a computational finance program. The Oregon Graduate Institute (OGI) School of Science and Engineering offered a computational finance program in 1996 (now discontinued) which was the first attempt to teach a program based on the computer science pedagogy. Mathematical finance programs have since emerged from higher profile institutions such as Stanford, Chicago, Columbia, Princeton, Cornell and MIT as well as from prestigious institutions in Europe. Myriad universities in Asia-Pacific also offer quant finance programs highlighting the growth in sophistication of the Asian markets.

Since the pioneering work of these universities in developing a quantitative finance program, the structure of the curriculum has remained virtually unchanged and almost identically replicated by universities across the globe. Universities generally house quantitative finance programs within their relevant business school, however some attempts have been made to integrate the program in other related disciplines such as mathematics, computer science or operations research. The use of mathematical finance is deeply ingrained in most financial institutions now more than ever before, but quantitative finance programs have generally adopted a one-size fits all approach to program delivery. In the long term, such rigid compliance with the existing suite of mathematical tools used for finance as well as indolence in program development may undermine the ability for the profession to evolve with the financial market. 


\subsection{The Role of Quants in Modern Finance}

Within the functional structure of the banking sector it is clear that the majority of quantitative research roles are centred in the investment banking sphere, see Figure 1. Quants are generally located in one of the two major functional divisions of financial institutions, namely the front office or middle office. The so-called front office refers to any area of a firm which is revenue generating whilst the socalled middle office refers to those areas which support the front office in their functions, but do not have direct responsibility for revenue generation.

Figure 1: Quantitative analyst skills required for various primary banking functions

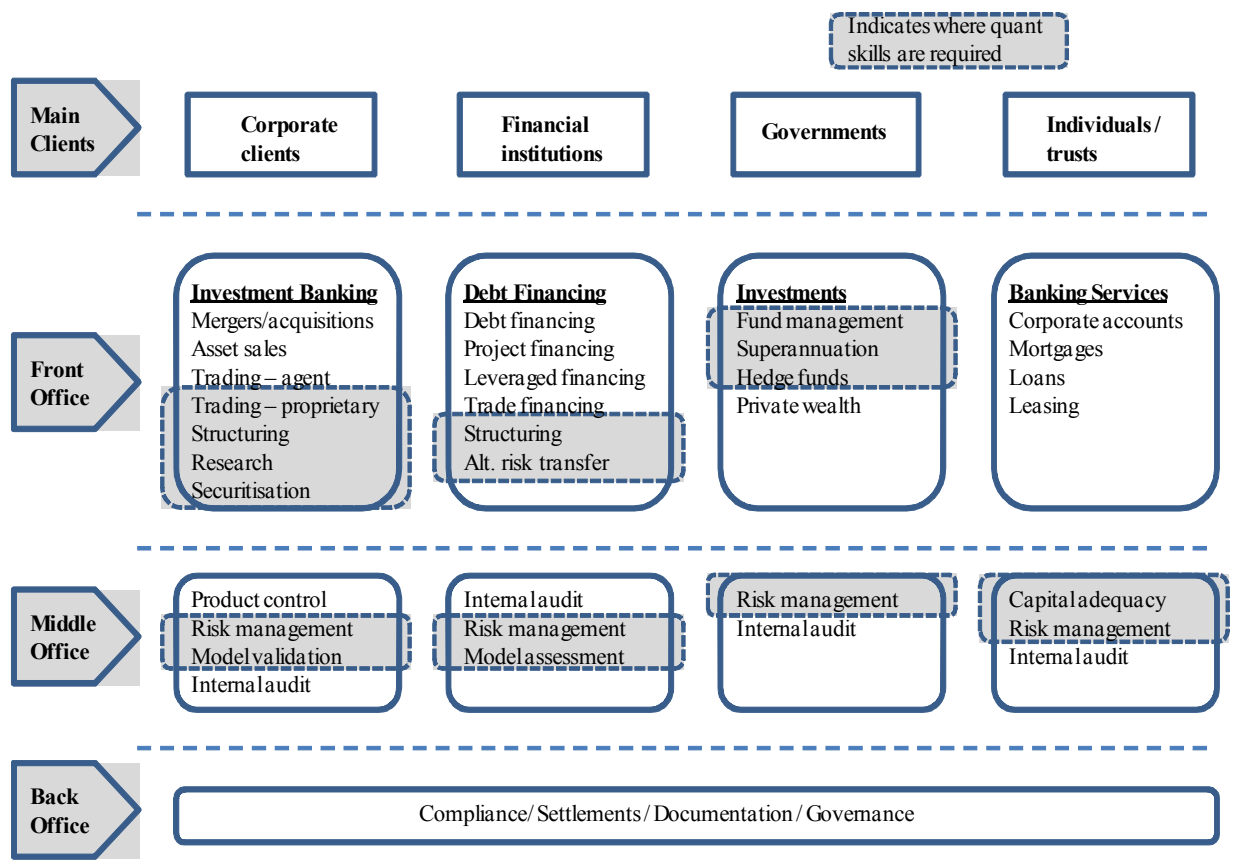

Quant teams are often very product aligned but sometimes they cover a portfolio of asset classes, particularly in smaller trading environments. Middle office quants are usually located in specific groups that act across asset classes in support of the front office. Some institutions view their quantitative teams as a dynamic resource shaping the strategy of the business while others use their quants as a secondary line of support, acting much like a safety net. No two institutions attribute equal importance to the role of financial mathematics in their businesses however they all attribute equally high importance to technology, which is where most quants come in handy. 


\subsection{Homogeneity of Mathematical Finance Programs}

Nearly every quantitative finance program focuses on the following core areas: Financial instruments, portfolio analysis, econometrics, financial risk management, credit risk, numerical analysis, computational methods, statistics, derivative security pricing, probability theory, stochastic processes and interest rate modelling. Each subject is taught with respect to the observed behaviour of financial markets, and is generally aimed to equip students with sufficient knowledge to apply mathematical finance at an entry level (Wilmott 2000).

But quantitative finance courses have adapted physics, mathematics and statistics techniques to the study of finance such that students from nonmathematical backgrounds emerge with a relatively narrow view of mathematics in general. University curricula choose a limited suite of concepts borrowed from mathematics, statistics and computer science largely based on existing popular research approaches to security valuation. This inevitably limits the capability of graduates to confidently develop unorthodox and alternative solutions to common financial problems. While the financial mathematics curriculum has become quite focussed, it still sits between academic chairs and never on any one of them. Rutledge and Raynes (2010) suggest that it is not possible to claim expertise in numerical analysis if one does not have at least a passing acquaintance with foundational elements such as z-transforms, Nyquist sampling theorem, convergence analysis and error propagation analysis, among others. Very few quant programs employ these concepts.

The study of quantitative finance has rapidly transformed from a loose collection of mathematical constructs in such areas as portfolio optimisation and derivative pricing to a very formal and structured course that covers specific mathematical approaches to valuation and risk. As such most quant finance programs are not considered to be a direct competitor to the MBA given its differing curriculum and goals. Indeed it is unlikely that an MBA or generalist finance graduate would be successful as a quant in the finance sector given the specialist mathematical knowledge required, and similarly it is generally rare for financial engineers to succeed in roles traditionally sought by MBA graduates.

From a firm perspective there is a key difference between recruiting for quant roles and for more generalist finance roles. Graduates interviewing for a managerial or sales job can secure a position based on brainpower, school pedigree or both, and graduation from a top-10 MBA school usually grants graduates access to the better finance roles. However in quant finance the pedigree is not so important - either an individual can program in an objectoriented language and understand stochastic calculus, or they cannot, and studying under a star professor does not carry decisive weight.

The tables in the Appendix list the best-known quant finance and general finance programs. Both the number of institutions offering degrees and the geographical diversity of these entities clearly illustrates growth in a dynamic and 
expanding industry. There are around 75 quant finance programs worldwide and the average number of students in each program is 25 , with some schools taking in almost 100 students and others accepting fewer than 15 (Nygaard 2005). Therefore there are around 2,000 reasonably well qualified quant finance graduates annually. For generalist finance there are around 50 postgraduate programs globally with around 1,300 graduates per annum. The combined total of over 3,000 graduate finance students in both general and quant finance worldwide is similar in number to the volume of MBAs churned out by just the top $10 \mathrm{US}$ business schools. While specialist finance graduates are becoming more abundant the quantity of graduates specialised in banking and finance are still relatively small.

Ardalan (2004) proposed the idea that observed behaviour in the financial market is not independent of financial theory. This approach represents the socalled functionalist paradigm of Burrell and Morgan (1979). Ardalan (2004) suggests that the functionalist paradigm has become dominant in mathematical finance. The implication of the functionalist paradigm is that since a growing number of graduates in financial mathematics are steadily influencing financial markets, the calibre and quality of their education which defines their perceptions, attitudes, beliefs and behaviours will in turn directly influence the practice of quantitative finance. This approach to quantitative finance is rooted in the tradition of economic positivism.

We conducted a survey of program design, program entrance requirements and the core areas of study for each of the institutions listed in Table A1 at Appendix A. The survey questions and survey results are listed at Appendix B. Among the 46 universities surveyed, 28 replied, a response rate of about 61 percent. The information received was analysed with respect to the core concepts taught at each institution. Without exception all programs taught quantitative methods that are focussed exclusively on the mathematical constructs established by the early pioneers of quantitative finance program development. The results from our study suggest that homogeneity in quant finance education and the similarity of quant finance practices appear to confirm Ardalan's thesis. In addition only around half of the programs required candidates to possess a degree in a scientific discipline and very few required the completion of an independent research project. The most telling result was that almost none of the programs require their graduates to complete a course in business ethics.

To quantify our analysis further, we used the Kendall rank correlation coefficient statistic to measure the association between each of the survey results. The Kendall $\boldsymbol{\tau}$ test is a non-parametric hypothesis test which detects statistical dependence between two variables. We use it here to assess the strength of the relationship between each of the questions in the survey. Each pair of observations from the survey was ranked. If the agreement between the two rankings is the same then $\boldsymbol{\tau}=\mathbf{1}$ but if the disagreement between the two rankings is perfect then the coefficient $\boldsymbol{\tau}=\mathbf{- 1}$. If each pair of observations is independent 
then $\boldsymbol{\tau}=\mathbf{0}$. The results are provided in Table B2 at Appendix B. There is a strong relationship between the provision of a tailored ethics course in both undergraduate and postgraduate studies, as well as ethics courses whose content is aligned with professional associations in financial services. However the relationship between ethics course offerings and both the use of a research project or the need for a scientific degree as a prerequisite for entry are less clear. These results suggest that some institutions offer a well developed suite of ethics courses within their quantitative finance program however most offer ethics as a nonessential component of a course that is largely aligned across institutions with similar entry requirements.

\section{Ethics in Quantitative Finance}

The treatment of ethics specific to the behaviour and responsibilities of quants has not been adequately addressed in the literature nor has it been integrated with the development of quant education. No postgraduate mathematical finance programs integrate the teaching of ethics and professional standards in their curricula and in fact very few programs even offer the teaching of ethics as an elective, as evidenced by our research. The coverage of ethics is left to the various industry associations that offer accreditation in risk management, investment analysis and mathematical finance. The universities who offer ethics courses usually simply adopt the curriculum developed by the CFA Institute covering their code of ethics and standards of professional conduct. The International Association of Financial Engineers does not consider ethics worthy of inclusion in their suggested core body of knowledge. Unless a quant is employed in an area requiring mandatory compliance through accreditation such as in risk management or as part of the regular compliance schedule of a financial institution to meet licensing conditions, the chances of a quant encountering ethics and professional standards education are slim.

An important but unanswered question concerns the actions of the most influential quants in the financial sector during the recent financial crisis. Even though there was general awareness of the scale of the exposures to nonperforming loans, why was there such little anticipation of the largest bank failures? Did their focus on internal risk levels undermine their anticipation of wider financial contagion? Or were they truly unaware of the leverage and the scale of exposures to underperforming assets across the global economy? Some soul-searching is underway in the wider profession, particularly by those who did not survive the crisis. The field of mathematical finance will continue to develop over the next 20 years and the existing foundations are likely to be replaced by less restrictive mathematical constructs. There are a range of new ideas challenging conventional theory with the common thread being that they use alternative mathematical approaches to classical finance and contain fewer 
assumptions. Uncertainty will continue to augment randomness in the modelling approach and underlying theories, which is expected to result in deriving price ranges for instruments rather than single values. In general a more "common sense" approach should return replacing blind reliance on mathematical models, while market incompleteness will be accepted and no longer feared. Mathematical finance is at a critical turning point given that many models used over the past 30 years have run their course. There is likely to be a major change in direction for future modelling efforts and the fiduciary responsibility to advance the field lies with the quant profession.

\subsection{A Fiduciary Role}

The role of the quantitative analyst is often mistaken to be a discipline free from ethical burdens. Quants typically uphold a unique and relatively powerful position to model and validate the value of complex derivative products for hedging and proprietary trading purposes. The models that are used to price such derivatives are usually beyond the mathematical understanding of the average financial accountant or even senior executive, so they rely heavily on the integrity of the quant who built them. The recent financial crisis has highlighted the role that mathematics has played since the 1970s in national and international finance. But are mathematicians really responsible for the crisis? At face value it is difficult to argue that they are, but there is evidence to suggest that they are at least partly responsible for some aspects of recent banking failures.

Some financial services firms are merely sellers of financial products and therefore only subject to the ordinary standards of trade practices. But most financial institutions selling products to consumers and companies are agents or fiduciaries and are therefore subject to conflicts of interest and the associated factors of trust relations. One of the main ethical issues in financial services concerns not only the risk but the suitability of a product for a client. Only the elements of risk are addressed through the legally-mandated product disclosure process. Deceptive sales practices and the concealment or obfuscation of information has resulted in successful litigation against institutions that failed to consider the financial sophistication of their clients and the relative suitability of the product they were sold. The first high-profile example of this was the 1996 out of court settlement between Procter and Gamble and Bankers Trust for a complex floating-rate swap structure, and there have been many since. The Bankers Trust quants who structured this instrument knew the true level of risk of the product which was based on relative changes in the interest rate yield curve, but failed to disclose the extent of such risks to Procter and Gamble. While quants often sit in subordinate roles to the sales teams, they have a responsibility to match product complexity with the level of client sophistication. Other abusive sales practices and poor quality financial products raise further ethical problems, particularly for 
individual investors as opposed to wholesale investors, explored in Frederick and Hoffman (1990).

\subsection{Ethical Interpretation of Mathematical Models}

Another aspect of the widening gap in the ethical practices of quants concerns derivative portfolio valuations for earnings reporting. For instance the Federal Home Loan Mortgage Corporation (Freddie Mac) was found to have understated its earnings in 2000-02. Of major concern was the improper accounting treatment of complex derivative security transactions which gave the firm the flexibility to continue meeting analyst earnings forecasts (OFHEO 2003). Subtleties in the models used for derivative valuation which are beyond the scope of understanding for financial accountants means that a large reliance is placed on the mathematical skills of their internal quant team to value the portfolio correctly and identify appropriate valuation sensitivities. The responsibility for quants to properly consider the full implications of model limitations has considerable bearing on firm performance. Improperly calibrated models used for derivative valuation forced Freddie Mac to restate its earnings which eventually resulted in negative reputational effects that contributed to a stock price decline of 31 percent over 2001-03. The quants not only failed to value the complex instruments correctly, they also undermined faith placed in all models used for security valuation which could have been avoided if the model limitations were correctly communicated to portfolio managers.

Lapses in quant model integrity can easily be misinterpreted as earnings manipulation. It has been well established in the literature that market forces make it difficult to create sustained levels of wealth through earnings manipulation (Danielson and Lipton 2010). Karpoff et al. (2008) showed that firms caught manipulating earnings results typically suffer harsh treatment by investors resulting in an average stock price decline of over 30 percent, with over 65 percent of this decline attributed to reputation effects. Tighter reins may therefore be placed on quant teams as a result of this concern.

The usual approach to combat ambiguity in fiduciary disclosure responsibilities is regulation. Federal legislation such as Sarbanes-Oxley (SOX) Act plays a role in prudential financial management through disclosures including a special provision for the forfeiture of profit or bonuses based on financial statements that later need to be re-stated (Beggs and Dean 2007). But it is difficult to see how more regulation, particularly through SOX and other new measures like the Dodd-Frank derivative reform bill can adequately address unethical practices specific to derivative valuation. The quality and integrity of quants will remain the key ingredient to accurate and appropriate security valuation. A simple but neglected approach is to ensure equally competent teams of quants in external auditors and regulators as in investment bank front offices. 
But so long as the front office quants continue to earn salaries that are multiples of their compatriots in auditing firms and regulators, a significant difference in competence is likely to persist.

The efficacy of the models themselves also raises interesting dilemmas. For instance, no two mathematical models used for pricing options will value a derivative the same. The difference in interest rate derivative valuation using a one-factor or a three-factor model is substantial, but it does not necessarily mean the values derived from the simpler one-factor model are less appropriate. Parsimonious models offer advantages in computation time, broader understanding of the model limitations among management and simpler risk management processes. But is a parsimonious model ethically superior to a more complex and probably more accurate model? When does a simple model become too simple? Within this context quants have a great deal of responsibility for getting the balance right between model completeness and parsimony. This has been partially addressed in the regulation ethics literature in terms of the trade-off between fairness and efficiency (Boatright 2010).

Soft dollars also feature as a key ethical issue for researchers in funds management. A soft dollar arrangement occurs when an investment manager directs the commission generated by a transaction towards a third party or inhouse party in exchange for services that are for the benefit of the client but are not actually client directed. Soft dollar proceeds are often redirected to internal research services. The use of client commissions to fund research with soft dollars has been heavily criticised as an unethical conflict of interest that may lead to fund managers favouring internal activities over fund investors. The ethical concern of soft dollars rests more with the conflict inherent in bundling the costs of research and execution into premium brokerage commissions than on the actual level of independence of the research (Johnsen 1994). However research quants are typically aware of the funding source which highlights the need for the research team to maintain a profile of independence in order to avoid unintended conflicts of interest. Many industry accreditation programs address this issue through their respective ethics and professional standards program but it is largely ignored in the specialist university programs.

Many other ethical issues confront the quant profession such as the effect of algorithmic trading on market stability, short-selling and regulatory arbitrage. Ethical behaviour is not comprehensively reinforced through securities legislation and the gap between them suggests that the only way to bridge the two is through a broader approach to ethics education. The current level of ethics education has barely touched the surface of these and other important factors. 


\subsection{Ethics Education for Financial Engineers}

The general assumption by many authors with regard to financial engineering ethics is that the solution to the lack of education is to introduce more courses, especially on ethics, and make them mandatory. Moreover, there is emphasis on classical ethics theories developed without financial engineering in mind. While such courses can be valuable by forcing students to think clearly, they do not meet the current need as efficiently as an approach that is intimately tied to financial engineering practice. Appropriate development in ethics education for quants is needed to identify points in the decision-making process where ethical questions can arise, and to explain how quants can protect stakeholders from the costs of unethical behaviour. An approach to ethics education needs to flexible and allow for different methods to infuse ethical coverage into the course (Danielson and Lipton 2010). In fact the integration of ethics can reinforce core financial concepts while not necessarily reducing the amount of time spent examining essential mathematical finance concepts (Beggs and Dean 2007, Danielson and Lipton 2010). The minimum content appropriate for an ethics reader in quantitative finance should include an overview of the main ethical issues in mainstream finance, the use and quality of regulatory codes as well as professional culture and character, implications of truthful financial reporting, the fiduciary and professional roles and responsibilities of quants, and an introduction to corporate social responsibility using quantitative finance techniques. The use of case studies in such a course, which are generally the most effective way to address ethical issues, would have the added benefit of broadening the experience of quants to consider matters of moral significance they may never have considered had they walked away from the trading floor to reflect on the cascading effects of their daily decisions.

\section{Conclusion}

Maintaining a team of high-quality quants is a source of competitive advantage for many financial institutions. In the recent crisis and other large financial failures quants must bear some responsibility for the limits of their models and the inadequate provision of tools to assist in managing financial risk. Existing quant education programs have a number of limitations not only in mathematical principles, but also in the broader consideration of ethics. Quants often encounter ethical decisions in which they generally have little experience. This is particularly hazardous given their role as the resident experts on the mathematical models used to measure and manage financial risk. Education programs in the quantitative finance profession have developed a great deal in the last 20 years however a missing ingredient is the integration of an understanding of business ethics and relevant professional standards. The credibility of the profession has 
suffered as a result of several high-profile financial losses, some of which could have been avoided if ethical considerations were integrated with the quantitative method. Ethics education should be a key feature of future mathematical finance programs to highlight the ethical dilemmas quants are likely to face in their careers. Such an approach will go some way towards aligning the profession with other specialisations in banking and avoid the need for complex and unnecessary regulation.

\section{Appendix A}

Table A1: Institutions offering masters degree programs in quantitative finance-related fields. * This is only a partial list - mathematical finance, financial engineering, financial mathematics and computational finance are among the types of degrees being offered (Source: Triana (2006), QuantNet, Wilmott)

\begin{tabular}{|l|l|}
\hline \multicolumn{2}{|c|}{ Quantitative Finance Programs* } \\
\hline UNITED STATES & OTHER COUNTRIES \\
\hline Baruch College & Birbeck College (UK) \\
\hline UC Berkeley & Boconni University (Italy) \\
\hline Boston University & University of Cape Town (South Africa) \\
\hline Claremont University & City University London (UK) \\
\hline Carnegie Mellon University & City University (Hong Kong) \\
\hline Columbia University (I) & University of Edinburgh (UK) \\
\hline Columbia University (II) & Erasmus University (Holland) \\
\hline Cornell University & HEC Montreal (Canada) \\
\hline University of Chicago & Imperial College (UK) \\
\hline DePaul University & Kings College London (UK) \\
\hline Florida State University & University of Manchester (UK) \\
\hline Fordham University & University of New South Wales (Australia) \\
\hline Georgia State University & University of Oxford (UK) \\
\hline Georgia Tech & Nanyang Tech (Singapore) \\
\hline Hofstra University & UTS (Australia) \\
\hline Kent State University & University of Toronto (Canada) \\
\hline University of Michigan & University of Warwick (UK) \\
\hline University of Minnesota & University of Waterloo (Canada) \\
\hline New York University Courant & York University (Canada) \\
\hline Oklahoma State University & \\
\hline University of Pittsburgh & \\
\hline Polytechnic University & \\
\hline Purdue University & \\
\hline Stanford University & \\
\hline University of Southern California & \\
\hline
\end{tabular}


Table A2: Institutions offering masters degree programs in general finance

\begin{tabular}{|l|l|}
\hline \multicolumn{2}{|c|}{ General Finance Programs* } \\
\hline UNITED STATES & OTHER COUNTRIES \\
\hline University of Alabama & University of Cambridge (UK) \\
\hline University of Arizona & City University London (UK) \\
\hline Boston College & ETH Zurich (Switzerland) \\
\hline Bentley College & HEC Paris (France) \\
\hline Brandeis University & HKUST (Hong Kong) \\
\hline Clark University & Instituto de Empresa (Spain) \\
\hline DePaul University & Imperial College (UK) \\
\hline University of Denver & London Business School (UK) \\
\hline George Washington University & LSE (UK) \\
\hline New School University & University of Manchester (UK) \\
\hline NYU Stern & University of Melbourne (Aust) \\
\hline Princeton University & University of Oxford (UK) \\
\hline Syracuse University & University of Toronto (Canada) \\
\hline Texas A\&M & University of Warwick (UK) \\
\hline Vanderbilt University & \\
\hline
\end{tabular}

* This is only a partial list. (Source: Triana (2006), QuantNet, Wilmott)

\section{Appendix B}

Questions asked to each University providing postgraduate quantitative finance programs:

1. Does your postgraduate quantitative finance program offer a tailored course in business ethics as a core subject?

2. Does your postgraduate quantitative finance program offer a tailored course in business ethics as an elective subject?

3. If your program offers a course on ethics is the course aligned with an industry body (such as CFA Institute)?

4. Does your course offer core subjects other than the following and if so can you list them: financial markets and instruments, portfolio analysis, financial econometrics, financial risk management, credit risk, mathematical finance, numerical analysis, computational methods, statistical methods, derivative security pricing, probability theory, stochastic processes and interest rate modelling. 
5. Does any component of your postgraduate quantitative finance program require delivery of a research project?

6. Is an undergraduate degree in a scientific discipline (mathematics, physics, chemistry, engineering, etc.) a prerequisite for program entry?

Results:

Table B1: Results of survey questions sent to 46 universities offering quantitative finance programs 2011 (28 universities responded with completed survey questions)

\begin{tabular}{|c|c|c|l|}
\hline Question & Yes (\# programs) & No (\# programs) & Remarks \\
\hline 1 & 2 & 26 & \\
\hline 2 & 11 & 17 & \\
\hline 3 & 8 & 3 & CFA Institute curriculum used \\
\hline 4 & 9 & 19 & Subject titles often differed \\
\hline 5 & 7 & 21 & One subject for research \\
\hline 6 & 15 & 13 & \\
\hline
\end{tabular}

Table B2: Results of Kendall $\tau$ rank correlation test for survey questions sent to 46 universities offering quantitative finance programs, 2011

\begin{tabular}{|c|c|c|c|c|c|}
\hline Pair & $\begin{array}{c}\text { Kendall } \\
\boldsymbol{\tau}\end{array}$ & p-value & Pair & $\begin{array}{c}\text { Kendall } \\
\boldsymbol{\tau}\end{array}$ & p-value \\
\hline$(1,2)$ & 0.9206 & $<0.001$ & $(2,6)$ & 0.1111 & 0.418 \\
\hline$(1,3)$ & 0.7407 & $<0.001$ & $(3,4)$ & 0.4491 & $<0.001$ \\
\hline$(1,4)$ & 0.6031 & $<0.001$ & $(3,5)$ & 0.3599 & 0.008 \\
\hline$(1,5)$ & 0.2910 & 0.031 & $(3,6)$ & 0.0371 & 0.797 \\
\hline$(1,6)$ & -0.1269 & 0.353 & $(4,5)$ & 0.2962 & 0.028 \\
\hline$(2,3)$ & 0.7460 & $<0.001$ & $(4,6)$ & 0.0687 & 0.621 \\
\hline$(2,4)$ & 0.5449 & $<0.001$ & $(5,6)$ & 0.3280 & 0.015 \\
\hline$(2,5)$ & 0.2222 & 0.101 & & & \\
\hline
\end{tabular}




\section{References:}

Ardalan, K. (2004), "On the Theory and Practice of Finance", International Journal of Social Economics, 31(7): pp. 684-705.

Bachelier, L. (1900), "Théorie de la Speculation”, Annales Scientifiques de l'École Normale Supérieure, 3(17): pp. 21-86.

Beggs, J. M. and Dean, K. L. (2007), "Legislated Ethics or Ethics Education? Faculty Views in the Post-Enron Era", Journal of Business Ethics, 71: pp. 15-37.

Boatright, J. R. (1996), "Business Ethics and the Theory of the Firm", American Business Law Journal, 34: pp. 217-238.

Boatright, J. R. (2010), Finance Ethics: Critical Issues in Theory and Practice, John Wiley \& Sons, New Jersey.

Black, F. and Scholes, M. (1973), "The Pricing of Options and Corporate Liabilities", Journal of Political Economy, 81: pp. 637-59.

Burrell, G. and Morgan, G. (1979), Sociological Paradigms and Organizational Analysis, Gower, Aldershot.

Danielson, M. G. and Lipton, A. F. (2010), "Ethics and the Introductory Finance Course", Journal of Business Ethics Education, 7: pp. 85-102.

Frederick, R. E. and Hoffman, W. M. (1990), “The Individual Investor in Securities Markets: An Ethical Analysis", Journal of Business Ethics, (9): pp. 579-589.

Johnsen, D. B. (1994), "Property Rights to Investment Research: The Agency Costs of Soft Dollar Brokerage", Yale Journal on Regulation, 11: pp. 75-113.

Karpoff, J. M., Lee, D. S., and Martin, G. S. (2008), "The Consequences to Managers for Financial Misrepresentation", Journal of Financial Economics, 88: pp. 193-215.

Markowitz, H. M. (1952), "Portfolio Selection", The Journal of Finance, 7(1): pp. 77-91.

Merton, R. C. (1973), "Theory of Rational Option Pricing”, Bell Journal of Economics and Management Science (The RAND Corporation), 4(1): pp. 141-183.

Nygaard, N. (2005), "Derivatives and the Demand for Financial Math - It Is Rocket Science", Derivatives 6(8): pp. 1-7.

Office of Federal Housing Enterprise Oversight (OFHEO) (2003), Report of the Special Examination of Freddie Mac.

Rutledge, A. and Raynes, S. (2010), Elements of Structured Finance, Oxford University Press, New York.

Samuelson, P. A. and Merton, R. C. (1974), "Generalized Mean-Variance Tradeoffs for Best Perturbation Corrections to Approximate Portfolio Decisions", Journal of Finance, 29(1): pp. $27-40$.

Sharpe, W. F. (1963), “A Simplified Model for Portfolio Analysis”, Management Science, 9(2): pp. 277-293.

Triana, P. (2006), Corporate Derivatives: Practical Insights for Real-Life Understanding, Risk Books, London.

Wilmott, P. (1998), Derivatives: The Theory and Practice of Financial Engineering, John Wiley \& Sons, London.

Wilmott, P. (2000), "The Use and Misuse of Mathematics in Finance", Philosophical Transactions of the Royal Society of London Series A - Mathematical Physical and Engineering Sciences, 358(1765): pp. 63-73. 
